This is a post-print version ${ }^{1}$. This article may not exactly replicate the final version published in the journal. The final peer-reviewed and edited copy of this manuscript is available here:

https://doi.org/10.1177/0266242620943371

Citation: Klonek, F. E., Volery, T., \& Parker, S. K. (2020). Managing the paradox: Individual ambidexterity, paradoxical leadership and multitasking in entrepreneurs across firm life cycle stages. International Small Business Journal, 1-24. https://doi.org/10.1177/0266242620943371

${ }^{1} \mathrm{~A}$ postprint is a digital draft of a research journal article after it has been peer reviewed and accepted for publication, but before it has been typeset and formatted by the journal 
Title: Managing the Paradox: Individual Ambidexterity, Paradoxical Leadership, and Multitasking in Entrepreneurs Across Firm Life Cycle Stages

\begin{abstract}
Ambidexterity requires both exploration and exploitation, but our understanding of the individual ambidexterity concept, its association with multitasking behaviours and paradoxical leadership across the firm life cycle of entrepreneurs is still very limited. In this study, we examined $N=4,355$ behavioural activities (exploration and exploitation) from twelve entrepreneurs. First, we showed that entrepreneurs displayed selfsustaining activity cycles. That is, exploration tended to be followed by exploration, and exploitation tends to be followed by exploitation. Second, when multitasking behaviours were high, entrepreneurs showed less ambidextrous switching. Third, we found an association between entrepreneurial ambidexterity and paradoxical leadership which was moderated by the firm life cycle stage. That is, paradoxical leadership and ambidexterity were positively associated in the start-up stage but disconnected in growth stages. Overall, our study contributes to a better understanding of individual ambidexterity, leadership and multitasking in entrepreneurs.

Keywords: ambidexterity, exploration, entrepreneurship, paradoxical leadership, switching
\end{abstract}


This is a post-print version ${ }^{1}$. This article may not exactly replicate the final version published in the journal. The final peer-reviewed and edited copy of this manuscript is available here:

https://doi.org/10.1177/0266242620943371

\section{Managing the Paradox: Individual Ambidexterity, Paradoxical Leadership, and Multitasking in Entrepreneurs Across Firm Life Cycle Stages}

Viewed literally, ambidexterity means the ability to use both hands with equal ease. In the literature, the concept has been referred to as an organisation's ability to adopt two seemingly contradictory behaviours - such as, for example, explore and exploit, be efficient and be flexible, or align and adapt (Gupta, Smith and Shalley, 2006; Hansen, Güttel and Swart, 2019). While much research has contributed towards our understanding of how ambidextrous organisations balance exploration and exploitation (Junni et al., 2013), scholars are increasingly acknowledging that these two processes largely also occur at the individual level (also referred to as 'personal ambidexterity', Bonesso, Gerli and Scapolan, 2014; Caniëls and Veld, 2019; Zacher, Robinson and Rosing, 2016). However, there are a number of unresolved questions within this literature - in particular, with respect to a better understanding of ambidexterity in individual entrepreneurs.

First, despite research focusing on individual ambidexterity in managers and (non-managerial) employees (Mu, van Riel, and Schouteten, 2020), we have a very limited understanding about ambidextrous activities in entrepreneurs. Yet, the question of how entrepreneurs engage in ambidextrous activities is central to an action- and process perspective on entrepreneurship, which sees entrepreneurship as a process "of discovery, evaluation, and exploitation of opportunities" (Shane and Venkataraman, 2000: 218). Using a process entrepreneurship perspective, ambidexterity is a phenomenon that is fundamentally tied to entrepreneurial activities, namely via the discovery (i.e., exploration) and exploitation of opportunities. This action- and process perspective on entrepreneurship extends beyond the view of entrepreneurs as selfemployed individuals and/or business owner-managers (Van Praag and Versloot, 2008) that are different from individuals employed by others or unemployed individuals. This business owner-managers perspective is particularly focused on the role of autonomy and ownership but gives less attention to the actual behaviours engaged in by entrepreneurs, which is our focus here.

Furthermore, the literature on individual ambidexterity suggests a switching process in which individuals change from exploration to exploitation and vice versa to reduce the inherent tensions of these competing activities (Bidmon and Boe- 
This is a post-print version ${ }^{1}$. This article may not exactly replicate the final version published in the journal. The final peer-reviewed and edited copy of this manuscript is available here:

https://doi.org/10.1177/0266242620943371

Lillegraven, 2019). Yet, a better understanding of how individuals engage in this switching process is largely missing. Unlike whole organisations that can deploy exploration to a research and development unit, and exploitation to a production unit, entrepreneurs have limited means to structurally separate these activities (Gupta et al., 2006). Thus, our first aim in this paper is to examine the systematic patterns of exploration and exploitation sequences over time. To realise this aim, we identify the unfolding patterns of close temporal sequencing between exploration versus exploitation activities in individual entrepreneurs. Close temporal sequencing of exploration and exploitation behaviours refers to the mechanism of temporally separating the two activities of exploration and exploitation into distinct but adjacent time periods (e.g., spending the first $30 \mathrm{~min}$. of an hour on exploration activities which is then followed by a $30 \mathrm{~min}$. period which is focused on exploitation activities). This concept is important from an innovation perspective which assumes that close temporal proximity of exploration and exploitation fosters synergies and drives innovative performance (Bledow et al., 2009; Gebert, Boerner and Kearney, 2010; Rosing and Zacher, 2017).

Second, we seek to better understand whether multitasking behaviours (i.e., engaging in more than one task during a typical work hour) are conducive or detrimental in helping entrepreneurs in switching between exploration and exploitation activities. This is an important question because entrepreneurs may think that multitasking is an effective way to deal with competing demands, yet it could also be argued that multitasking already consumes important cognitive resources, which makes it harder to switch between exploration and exploitation activities.

Third, we need a better understanding of how leadership in entrepreneurs and ambidexterity are connected. A recent review on this topic which covered 146 articles, only identified five empirical studies that have focused on entrepreneurial leadership and concluded that a "leadership perspective appears underutilised in (...) entrepreneurship research" (Gorgievski and Stephan, 2016: 446). However, it is crucial to understand how entrepreneurial leadership could impact on how entrepreneurs manage inherent tensions arising from exploration and exploitation requirements. This is critical because entrepreneurs (in contrast to leaders and managers that work within organisations) need to both manage exploration-and-exploitation of new and existing 
This is a post-print version ${ }^{1}$. This article may not exactly replicate the final version published in the journal. The final peer-reviewed and edited copy of this manuscript is available here:

https://doi.org/10.1177/0266242620943371

business opportunities, while concurrently lead their followers. Hence, we need to understand how leadership in entrepreneurs is either conducive or detrimental for individual ambidexterity.

Overall, we make two contributions to the literature with this study. First, we contribute knowledge to the literature on individual ambidexterity, in particular, by answering the question of how individuals sequentially switch between exploration and exploitation over time (Bidmon and Boe-Lillegraven, 2019; Mu, van Riel and Schouteten, 2020). We focus on sequential patterns of ambidextrous behaviour and theorise that entrepreneurs are more likely to maintain their activity patterns. These patterns are self-sustaining cycles in which exploration sustains further exploration activities, whereas exploitation sustains further exploitation activities. Furthermore, we show that multitasking behaviours further reduce the likelihood of switching between these opposing activities.

Second, we contribute to the still nascent literature on entrepreneurial leadership, that is, how entrepreneurs influence and direct the performance of their employees "towards the achievement of those organisational goals that involve recognising and exploiting entrepreneurial opportunities" (Renko et al., 2015: 62). Despite conceptual arguments that entrepreneurship and leadership share important linkages (Cogliser and Brigham, 2004), empirical research focusing on entrepreneurial leadership is still not well developed, with literature reviews only identifying very few empirical studies (Gorgievski and Stephan, 2016; Koryak et al., 2015; Leitch and Volery, 2017). We seek to understand how individual ambidexterity is associated with a paradoxical entrepreneurial leadership style. Whereas ambidexterity entails individual exploitationexploration activities, paradoxical leadership refers to how the entrepreneurs (and managers) deal with competing demands of their followers (Alfes and Langner, 2017). Our study thus evaluates whether individual ambidexterity is also linked with a paradoxical leadership style in entrepreneurs. In addition to this, we clarify how the life cycle of a company (i.e., the stage of maturity of a company which involves a unique configuration of the organisational context, strategy, and structure (Lester, Parnell and Carraher, 2003; Sirmon et al., 2011) affects the relationship between individual ambidexterity and paradoxical leadership (Hanks and Chandler, 1994; Lester et al., 
This is a post-print version ${ }^{1}$. This article may not exactly replicate the final version published in the journal. The final peer-reviewed and edited copy of this manuscript is available here:

https://doi.org/10.1177/0266242620943371

2003). Specifically, we show that the firms life stage changes the relationship between individual ambidexterity and paradoxical leadership.

\section{THEORETICAL FRAMEWORK AND HYPOTHESES}

\section{The Micro-level Foundations of Individual Ambidexterity}

At the individual level, ambidexterity has been introduced as a concept to both describe the behaviour of managers (e.g., Mom, Van Den Bosch and Volberda, 2009) and employees (Rosing and Zacher, 2017). To illustrate, Mom et al. (2009: 812) defined individual ambidexterity as a “manager's behavioural orientation towards combining exploration and exploitation related activities within a certain period of time." More specifically, exploration at the manager-level refers to activities around flexibility, the development of new market possibilities, strong renewal, and the acquisition of new skills. On the other hand, managerial exploitation encompasses activities focusing on efficiency, short-term goals and routine processes, which only require existing knowledge.

The literature on (non-managerial) employee ambidexterity similarly defines individual exploration as "behaviours related to experimentation, searching for alternative ways to accomplish a task, and learning from errors" and exploitation as "relying on previous experience, putting things into action, and incrementally improving well-learned actions" (Rosing and Zacher, 2017: 695-696; cf., Caniëls and Veld, 2019; Kauppila and Tempelaar, 2016; Kobarg et al., 2017). Taken together, scholars have conceptualised individual ambidexterity as a "self-regulated activity that combines individual exploration and exploitation" (Mu, van Riel and Schouteten, 2020: 7). More importantly, researchers noted that individual ambidexterity seems to be particularly relevant in the context of small business enterprises $(\mathrm{Mu}$, van Riel and Schouteten, 2020; Yeganegi et al., 2019).

Different approaches exist in the literature with respect to conceptualising individual ambidexterity as an orthogonality (i.e., two independent activities that can be carried out simultaneously, e.g., Chang et al., 2016; Mu et al., 2020; Zacher et al., 2016) or as a continuity (i.e., two-ends of one spectrum that can only be carried out consecutively, e.g., Ahmadi et al., 2017; Bledow et al., 2009; Bidmon and BoeLillegraven, 2019; Håkonsson et al., 2016). While we acknowledge that there is no 
This is a post-print version ${ }^{1}$. This article may not exactly replicate the final version published in the journal. The final peer-reviewed and edited copy of this manuscript is available here:

https://doi.org/10.1177/0266242620943371

universal argument in favour of either continuity or orthogonality, this issue can be resolved by taking a closer look at the context (and level) in which the phenomenon is studied (cf., Gupta et al., 2006). Gupta et al. (2006) argued that researchers who are interested in ambidexterity in individuals (such as entrepreneurs) can assume that exploration and exploitation will generally be mutually exclusive. In contrast, research on exploration and exploitation in larger units of analyses (such as teams or organisations) could take an orthogonal perspective as teams (and organisations) can theoretically simultaneously engage in both activities by allocating these activities to different team members (or departments). Based on these arguments, we adopted an either-or concept of ambidexterity in which entrepreneurs either engage in exploration or in exploitation.

Scholars have also described different regulatory mechanisms in order to address this duality. The literature on individual ambidexterity (Bidmon and Boe-Lillegraven, 2019; Mu et al., 2020; Zacher et al., 2016) has recognised that ambidexterity requires some mechanisms of balancing (or separation) to reconcile the tensions between performing exploration and exploitation activities. While organisations have the potential to pursue exploration and exploitation concurrently via allocating these activities to different business units (organisational separation, Lavie, Stettner and Tushman, 2010), individuals have to rely on temporal separation (i.e., shifting) between exploration and exploitation activities (Bidmon and Boe-Lillegraven, 2019; Keller and Weibler, 2015). In fact, at the individual level, "exploration and exploitation involve different modes of human attention, (...) [and thus] cannot be pursued simultaneously" (Keller and Weibler, 2015: 57). This temporal perspective on ambidexterity, in which both exploration and exploitation are sequentially separated over time, requires research designs that track within-person changes over time.

Most importantly, the emerging individual ambidexterity research stream has yet to establish how 'close' the integration of exploration and exploitation needs to be. That is, research needs to disentangle the temporal fluctuations of exploration and exploitation activities (Rosing and Zacher, 2017). One major problem with this call for research is that "we almost never know what this optimal [sampling] time interval is, even if we have a relatively sound theory of the change phenomenon. This is because our theories of research phenomena are often static in nature." (Wang et al., 2017: 10). 
This is a post-print version ${ }^{1}$. This article may not exactly replicate the final version published in the journal. The final peer-reviewed and edited copy of this manuscript is available here:

https://doi.org/10.1177/0266242620943371

Hence, our research builds on recommendations from Wang et al., (2017) who pointed out that "even when our theories are dynamic and focus on change processes, they are almost always silent on the specific length of the temporal dimension through which the substantive processes occur over time." (2017: 10). To better understand these change processes, that is, how micro-switches ${ }^{1}$ from exploration to exploitation occur in entrepreneurs, our study follows recent developments for using observational research to study switching behaviour in exploration and exploitation activities (Bidmon and Boe-Lillegraven, 2019; Håkonsson et al., 2016). That is, we applied a continuous highresolution assessment on micro-level exploration and exploitation activities.

\section{Individual Ambidexterity: Behavioural Tendencies to Switch between Exploration and Exploitation}

Understanding how entrepreneurs shift between exploration and exploitation is key to developing a theory about the paradoxical nature of ambidexterity as an individual behavioural construct (Bidmon and Boe-Lillegraven, 2019). Early conceptual work on ambidexterity suggested that both activities should be self-reinforcing. For example, March (1991) argued that "exploitation often leads to early success, reinforcing exploitation but crowding out the risk-taking and broad search needed for exploration" (Mom et al., 2009: 5). Similarly, exploration often leads to failure associated with new ideas, as it pushes aside attention to reliability and efficiency which are central to exploitation. Yet, empirical work that examines whether such selfreinforcing mechanisms occur in individual behaviours is almost non-existent. To the authors knowledge, there is only one study which has so far explored the affective, cognitive, and behavioural reactions in individuals when they are switching from exploration to exploitation, and vice versa (Bidmon and Boe-Lillegraven, 2019). The qualitative and observational research study from Bidmon and Boe-Lillegraven (2019) investigated the response patterns of individuals unfolding around 38 situations during which switching between the two activities occurred. The authors proposed a theoretical process model in which switching requests (i.e., reminding participants who were

\footnotetext{
${ }^{1}$ With micro-switches, we mean changes in a behavioural phenomenon like ambidexterity that involve how the changes in behavioural activities of exploration and exploitation occur within a behavioural sequence of activities (Bidmon and BoeLillegraven, 2019).
} 
This is a post-print version ${ }^{1}$. This article may not exactly replicate the final version published in the journal. The final peer-reviewed and edited copy of this manuscript is available here:

https://doi.org/10.1177/0266242620943371

exploring or exploiting to then switch towards exploitation (or exploring), and vice versa) were associated with strong negative emotional reactions (e.g., confusion, dissatisfaction, even anger and agitation) and displays of cognitive exhaustion (e.g., appearing tired, having circular discussions). These reactions then manifested in behavioural displays of resistance, that is, participants often ignored the switching cue or actively argued that they needed more time to focus on the current activity. This qualitative study thus suggested that ambidextrous switching in individuals is cognitively and emotionally effortful and, therefore, that individuals tend to maintain one of the two activities.

While the mechanisms that drive this resistance towards switching are still unclear, neuroscientific research has shown that switching between exploration and exploitation by individuals is associated with modulation of neurological attention systems that shift between a phasic mode (i.e., control state that narrows attention which is associated with exploitation) to a tonic mode (withdrawal of control that broadens attention which is associated with exploration) (Laureiro-Martinez, Brusoni and Zollo, 2010). Essentially, these neurocognitive modes (i.e., broad versus narrow attention) cannot be maintained concurrently and switching is associated with additional cognitive efforts. In line with this argument, research on individual ambidexterity has shown that managers who try to balance both exploration and exploitation experience greater levels of cognitive strain (Keller and Weibler, 2015). In sum and drawing on this existing theorising and research, we posit that entrepreneurs are more likely to sustain one type of activity over time (e.g., exploitation) instead of switching frequently between exploration and exploitation.

Hypothesis 1: Individual ambidexterity draws on self-sustaining cycles whereby exploration activities are followed by exploration activities. Conversely, exploitation activities are followed by exploitation activities.

\section{The Role of Multitasking on Behavioural Switching between Exploration and Exploitation Activities}

We are also interested in how multitasking of entrepreneurs facilitates (or inhibits) their capacity to switch from exploration to exploitation (or from exploitation to exploration activities). In particular, we propose that multitasking behaviours in 
This is a post-print version ${ }^{1}$. This article may not exactly replicate the final version published in the journal. The final peer-reviewed and edited copy of this manuscript is available here:

https://doi.org/10.1177/0266242620943371

entrepreneurs reduces the likelihood of switching between exploration and exploitation. Multitasking behaviours at work have been defined as "work[ing] on more than one task during a typical work hour" (König et al., 2010: 99). While there is rich literature that has studied multitasking as a neuro-cognitive process within controlled laboratory studies (Salvucci and Taatgen, 2008) and some research that focuses on multitasking abilities (Sanderson et al., 2013), we focus on the concept of multitasking behaviours across the work day (Kirchberg et al., 2015; König et al., 2010). To better understand multitasking behaviours, we are relying on the multitasking continuum which allocates multitasking behaviour in terms of the time spent (e.g., seconds to hours) on one task before switching to another (Salvucci, Taatgen and Borst, 2009). The lower end of this spectrum (i.e., seconds) is referred to as concurrent multitasking, that is, task switches are happening within seconds (e.g., listening while note-taking) to minutes (e.g., watching a game while talking to a friend), whereas the higher end of this spectrum is referred to as sequential multitasking, which means that task switches are occurring over minutes to hours (e.g., writing a paper and reading an email).

Switching while multitasking requires a substantial amount of cognitive resources and effort, as evidenced by the research on switching costs (Salvucci et al., 2009). In other words, participants need more processing time to retrieve relevant information from their memory when they switch from one task and resume another task (Monsell, 2003). Cognitive psychology research suggests that after a task switch, individuals have slower response times and make more errors (Monsell, 2003). In cognitive psychology, there are also multiple experimental studies that indicate that multitasking is negatively related with task performance (Adler and Benbunan-Fich, 2012, 2013; Buser and Peter, 2012; Pashler, 2000). The argument that multitasking requires cognitive resources is further supported by evidence from workplace studies, which have shown that multitasking is increased when work demands are high (König et al., 2010) and that multitasking is associated with a decrease in work performance (Kirchberg et al., 2015). At the same time, cognitive resources and attentional control are also required when individuals switch between exploration to exploitation (LaureiroMartinez et al., 2010), as evidenced by switching resistance, that is, a tendency to prioritise either exploration or exploitation activities (Bidman and Boe-Lillegraven, 2020). Overall, we argue that entrepreneurs who show high levels of multitasking 
This is a post-print version ${ }^{1}$. This article may not exactly replicate the final version published in the journal. The final peer-reviewed and edited copy of this manuscript is available here:

https://doi.org/10.1177/0266242620943371

behaviours have less cognitive resources to engage in effortful ambidextrous switching behaviours. Thus, taken together, we hypothesise:

Hypothesis 2: Multitasking is negatively related with behavioural switching between exploration and exploitation behaviours.

\section{Individual Ambidexterity and Paradoxical Leadership}

A third question with respect to ambidextrous behaviours is how this concept is related to leadership styles, such as paradoxical leadership. Using a paradox theory lens (Schad et al., 2016; Smith and Lewis, 2011), paradoxical leadership has been defined as "seemingly competing, yet interrelated, leadership behaviours employed to meet competing follower demands simultaneously and over time" (Alfes and Langner, 2017: 97). Specifically, leaders who show both participative but also directive behaviours have been classified as paradoxical leaders (Alfes and Langner, 2017). Participative behaviour "involves joint decision-making or shared influence in decision-making, sharing information with others, holding [employees] accountable, and giving (...) autonomy and flexibility in their work." (Alfes and Langner, 2017: 98). While participatory behaviours help in dealing with environmental uncertainties and allow enough freedom to stay flexible in unforeseen business disruptions, solely relying on this type of leadership may also result in a lack of role clarity for employees and an unstructured working environment. Therefore, the other pole of paradoxical leadership entails directive behaviours which involve giving directions and monitoring specific milestones (Alfes and Langner, 2017).

To date, the literature on paradoxical leadership has investigated to which extent paradoxical leadership fosters employee innovation (Kauppila and Tempelaar, 2016; Zacher et al., 2016). Whilst paradoxical leadership and entrepreneurial ambidexterity are different phenomena that are determined by distinct motivations and capability sets, we expect that - because they involve a set of complementary variance-increasing and variance-decreasing behaviours (March, 1991) _ paradoxical leadership and entrepreneurial ambidexterity will be positively associated.

Furthermore, previous research suggests that both ambidexterity and paradoxical leadership are enabled via a common set of antecedents (Good and Michel, 2013; Laureiro-Martinez et al., 2010). For example, Good and Michel (2013) focused on the 
This is a post-print version ${ }^{1}$. This article may not exactly replicate the final version published in the journal. The final peer-reviewed and edited copy of this manuscript is available here:

https://doi.org/10.1177/0266242620943371

cognitive antecedents of individual ambidexterity, showing that cognitive performance in the Stroop Task (a measure of cognitive flexibility) explained variances in individual ambidexterity above and beyond general intelligence measures. Moving beyond cognitive antecedents, contextual factors may also have an influence on individual ambidexterity and paradoxical leadership. For example, organic (i.e., flexible and decentralised) in contrast to mechanistic (i.e., rule-based and centralised) organisational structures have been hypothesised to foster paradoxical leadership (Smith and Lewis, 2011). In a similar vein, flexible work structures and enriched jobs have been argued to foster individual ambidexterity (Mom et al., 2009; Parker, 2014). Since successful entrepreneurs show high levels of cognitive flexibility (Dheer and Lenartowicz, 2017) and operate within organic work structures, we argue that individual ambidexterity and paradoxical leadership are determined by a similar set of antecedents. Thus, we hypothesise:

Hypothesis 3: Paradoxical leadership is positively related with individual ambidexterity.

\section{The Influence of Firm Life Cycle on Individual Ambidexterity and Paradoxical Leadership}

Finally, we are interested in how the association between paradoxical leadership and individual ambidexterity in entrepreneurs is modulated by contextual factors. A strong contextual factor is the firm life cycle which has been argued to affect the behaviours as well as leadership styles of entrepreneurs (Mathias, Mckenny and Crook, 2018). Firm life cycle theory suggests that companies can be characterised by distinct stages of maturity (Lester et al., 2003; Sirmon et al., 2011). These maturity stages describe how companies differ with respect to the organisational situation (e.g., the size of a firm, number of owners/shareholders, the heterogeneity of the market), the organisational structure (informal to formal), the decision-making styles of the entrepreneur, and the competitive strategy (cf., Lester et al., 2003). More importantly, different life cycle stages would require different behavioural activities of the entrepreneur in order to manage the company (Sirmon et al., 2011). Most life cycle theories distinguish between four to five different stages of the company, such as, startup stage, growth stage, maturity stage, saturation stage, and a recession stage (Sirmon et 
This is a post-print version ${ }^{1}$. This article may not exactly replicate the final version published in the journal. The final peer-reviewed and edited copy of this manuscript is available here:

https://doi.org/10.1177/0266242620943371

al., 2011) $)^{2}$. In the following, we will focus on the start-up stage and the growth stage of the company and argue how these stages affect the relationship between entrepreneurial ambidexterity and paradoxical leadership. That is, we will describe the start-up stage and the growth stage in more depth. With respect to the start-up stage, companies are usually characterised as being still relatively small and serving a homogenous market. In the start-up stage, entrepreneurs usually operate within an informal structure, that is, they can use a centralised decision-making style with a focus on trial and error (Lester et al., 2003). The entrepreneur has identified an opportunity and he/she formulates the initial vision and goals to influence others to join him/her as investors, employees, customers, buyers and so forth. Since the business is not fully established, roles and structures are dynamic and the entrepreneur has to be a jack-of-all-trades (Kanzanjian and Drazin, 1990). We argue that this organic context of these start-up stage companies is both conducive to individual ambidextrous behaviour as well as to a paradoxical leadership style.

With respect to the growth stage, entrepreneurs need to focus on expansion in production and sales, additional specialisation in manufacturing, marketing, and in hiring administrative roles (Hanks and Chandler, 1994). In growth stage companies, entrepreneurs need to delegate more tasks to newly hired staff. This transfer of responsibility and control to other employees is often associated with changes in the organisational structure, work processes, and routines. An examination of how organisations age and grow suggests that they "drift over time towards more structure and greater emphasis on efficiency" (Eisenhardt, Furr and Bingham, 2010: 1265). Thus, entrepreneurs in growth stage companies are more likely to take on organisational tasks, coordinate activities, and build up an efficient system.

Taken together, start-up stage companies incorporate a set of antecedents (i.e., organic and flexible work structures) that enable both individual ambidexterity and paradoxical leadership. However, within the growth stage of the firm, entrepreneurs are operating within a more formal and rule-based organisational structure and these characteristics should weaken the association between individual ambidexterity and paradoxical leadership.

\footnotetext{
${ }^{2}$ Different names of these stages have been proposed in this literature (e.g., start-up, expansion, consolidation, diversification, and decline, Lester et al.,2003)
} 
This is a post-print version ${ }^{1}$. This article may not exactly replicate the final version published in the journal. The final peer-reviewed and edited copy of this manuscript is available here:

https://doi.org/10.1177/0266242620943371

Hypothesis 4: The firm life cycle moderates the relationship between paradoxical leadership behaviours and ambidexterity, such that this relationship is stronger in the start-up firms and weaker in growth firms.

\section{Method}

\section{Design}

We applied an ecological momentary assessment (EMA) design to capture the temporal and within-person variations of individual ambidexterity and paradoxical leadership in entrepreneurs over time (Uy, Foo and Aguinis, 2010). That is, we conducted a real-time assessment of behavioural activities in entrepreneurs. EMA designs capture characteristics of the environment (e.g., location, time of day, exploration/exploitation behaviours) that change over time and are particularly suited to enhance ecological validity in entrepreneurship research and study entrepreneurs in their natural environment (Uy et al., 2010).

\section{Sample}

We selected a sample of 12 entrepreneurs operating in Switzerland, Austria, and Germany. Six entrepreneurs were in a start-up phase (i.e., companies that had been incorporated for no more than 12 months; $M=0.54$ years) and six were growth-oriented companies (mean company age $=7.6$ years). All entrepreneurs were the founders and owner-managers of their companies. In addition, entrepreneurs in growth-stage companies were all recipients of the EY 'Entrepreneur of the Year', an award for founders of growth-oriented, innovative business ventures. With this screening criteria we wanted to ensure that we identified entrepreneurs with a strong innovation and growth track record, rather than traditional small business owner-managers. The entrepreneurs came from a wide range of industries, including contract manufacturing, medical technology, retail, building, software development, and internet services. Table 1 provides an overview of the sample (i.e., company characteristics, industry in which the entrepreneurs operated, and their growth performance).

\section{++++ Insert Table 1 here++++}

\section{Data Collection}

We used structured observations to capture the nature of the entrepreneur's behaviour. Structured observation makes it possible to "couple the flexibility of openended observation with the discipline of seeking certain types of structured data" 
This is a post-print version ${ }^{1}$. This article may not exactly replicate the final version published in the journal. The final peer-reviewed and edited copy of this manuscript is available here:

https://doi.org/10.1177/0266242620943371

(Mintzberg, 1973: 231). A team of three researchers shadowed each entrepreneur in his/her natural setting over four days, during a total of 567 hours. To ensure that our observations were representative of the entrepreneur's behaviour, we selected a set of workdays that were not affected by unusual planned activities. Therefore, we did not necessarily conduct observations over consecutive days. We recorded every action the entrepreneurs performed, following the idea that entrepreneurial behaviour is composed of "discrete units of individual activity that can be observed by an audience" (Bird and Schjoedt, 2009: 335). Table 2 shows a sample of the actions captured with the observation template.

$$
\text { ++++Insert Table } 2 \text { here }++++
$$

\section{Measures of Individual Ambidexterity}

Exploration and exploitation were coded based on the real-time observations of entrepreneurial actions throughout the day. This resulted in a series of actions (microevents) that were sequenced using Newtson's (1973) break points-moments, that is, a new action was coded whenever the location, the medium of communication, the individuals present, or the focus of the action changed. Every action-unit was timestamped (onset and offset) and labelled with a short transcript that described the specific actions taken by the entrepreneur (see Table 2). In total, our observations captured 4,355 events of exploration and exploitation activities. This type of timed-event categorical measurement allowed us to capture changes in exploration and exploitation behaviours on two-time spans (micro-events of exploration and exploitation; and a continuous measure of hourly ambidexterity).

\section{Micro-event Level Ambidexterity}

Micro-event level ambidexterity refers to the smallest unit of analysis, that is, activity units of exploration versus exploitation. The categorisation of all activity units into exploration and exploitation was theoretically grounded in the ambidexterity literature (Gupta et al., 2006; March, 1991). Entrepreneurial actions were coded as exploration when they related to searching, recognising, exploring, or enacting opportunities (e.g., working on the software for a prototype). Conversely, entrepreneurial actions were coded as exploitation when they related to the implementation and execution of existing opportunities (e.g., choosing a software to increase productivity). 
This is a post-print version ${ }^{1}$. This article may not exactly replicate the final version published in the journal. The final peer-reviewed and edited copy of this manuscript is available here:

https://doi.org/10.1177/0266242620943371

As such, our methodological approach aligns with the theoretical perspective that sees exploration-exploitation as competing activities (Ahmadi et al., 2017; Gupta et al., 2006; Håkonsson et al., 2016, March, 1991), such that individual entrepreneurs have to make an either-or decision and cannot engage simultaneously in both activities.

The observers followed best-practice guidelines in ensuring high reliability by engaging in regular discrepancy discussions, thus helping to achieve a coder reliability of 85 percent. On average, these micro-events had a duration of about seven minutes. We used this level of analysis and the nominal timed-event sequential data to test sequential patterns of exploration and exploitation over time (hypothesis 1).

\section{Validity of Coding Exploration and Exploitation}

To assess the validity of the coded behaviours for each micro-event, we performed linguistic content analyses (McKenny, Short and Payne, 2013) on all transcribed activities that were linked to exploration versus exploitation. To do this, we used the linguistic inquiry and word count (LIWC) 2015 software (Tausczik and Pennebaker, 2010; Wolf et al., 2008). LIWC quantifies the percentage of words in written text by comparing each word to a list of words within an internal lexical category (Appendix I). We used five lexical categories of the LIWC that distinctively map on the theoretical features of exploration versus exploitation, namely temporal foci ("past," "present," "future"), possibilities ("tentativeness"), and money salience ("money"). Temporal foci are defined as "allocation of attention to the past, present, and future" (Shipp, Edwards and Lambert, 2009: 2) and a future focus is associated with envisioning what the future is likely to bring. Concurrently, exploration has been conceptualised as a long-term activity with unclear outcomes in the distant future (e.g. Mom et al., 2009; Tuncdogan and Dogan, 2019). Exploration involves the development of new market possibilities, strong renewal, or even the acquisition of new skills - all activities that have a long-term future focus. In contrast, exploitation is focused on efficiency, short-term goals, implementation, and refinement (e.g., March, 1991; Mom et al., 2009), all activities which are essentially short-term in nature and result in more immediate outcomes. Furthermore, exploitation involves application of existing knowledge and thus also makes use of know-how from the past, that is, things that have worked well in the past. Based on these arguments, we expected that exploitation (in contrast to exploration) has a higher level of present focus and of past focus. 
This is a post-print version ${ }^{1}$. This article may not exactly replicate the final version published in the journal. The final peer-reviewed and edited copy of this manuscript is available here:

https://doi.org/10.1177/0266242620943371

With respect to tentativeness, another core feature of exploration involves tentative trial-and-error activities, whereas exploitation is focused on activities that produce certain outcomes (March, 1991; Mom et al., 2009). Hence, we selected the LIWC category "tentativeness" because it focuses on linguistic markers like “depending”, "hope”, “almost”, "luck", "maybe”, "probably” etc. (Chen, Crossland and Luo, 2015) and thus expected exploration (in contrast to exploitation) to have a higher extent level in this category.

With respect to money salience, exploitation should generate direct income since it capitalises on using existing firm capabilities (Lavie et al., 2010), whereas exploration is risky and may not result in sales or any monetary inputs (Junni et al., 2013). Metaanalytic evidence suggests that exploitation (unlike exploration) shows a positive and significant correlation with profits $(r=.12)$, whereas exploration (unlike exploitation) is positively linked with growth ( $r=.18$ ) (Junni et al., 2013). Hence, we used the LIWC dictionary which screens for words like "rich", "sale", "wealth", "finance" etc, and thus operationalised the money-related terms used when entrepreneurs engage in their activities. The money lexicon has previously been used to measure or classify moneyrelated concepts in online environments which provide text-based data, such as monetizing user activities in social network posts (Nagarajan et al., 2009), using moneyrelated words when making requests in online appeals (Althoff, Salehi and Nguyen, 2013), eat-out preferences from Twitter posts (Rahman et al., 2016), and money saliency in the context of crowdfunding research (Chan et al., 2019).

As expected, exploitation contained a significantly higher level of past-focus ( $M$ $=1.80, S D=5.30)$, present-focus $(M=6.5, S D=9.45)$, and money-salience $(M=5.14$, $S D=10.26$ ) in comparison to exploration activities (past: $M=1.04, S D=2.92, p<$ 0.01 ; present: $M=4.47, S D=7.5, p<0.01$; money-salience: $M=3.54, S D=8.39, p<$ $0.01)$. Conversely, exploration activities were higher in tentativeness $(M=0.70, S D=$ $2.61)$ and future-focus $(M=0.56, S D=2.03)$ in comparison to exploitation (tentativeness: $M=0.40, S D=2.13, p<0.01$; future-focus: $M=0.52, S D=2.43, p=$ $0.70)$. Overall, these linguistic content analyses further support the validity of the coded activities.

\section{Multitasking and Ambidextrous Switching Behaviours}


This is a post-print version ${ }^{1}$. This article may not exactly replicate the final version published in the journal. The final peer-reviewed and edited copy of this manuscript is available here: https://doi.org/10.1177/0266242620943371

For hypothesis 2, we wanted to test whether variations in multitasking behaviours were negatively associated with switching between exploration-exploitation sequences or exploitation-exploration sequences. To do this, we counted the number of times that each entrepreneur showed sequential switches (exploration(lag0)-toexploitation(lag1), or exploration(lag0)-to-exploitation(lag1) within each working hour.

\section{Multitasking Behaviour}

Multitasking behaviour at work has been conceptualised as "work[ing] on more than one task during a typical work hour" (König et al., 2010: 99). We used an objective operationalisation and captured multitasking by counting the number of different tasks that entrepreneurs performed within one work hour $(M=8.57, S D=5.82$, Min $=1$, Max =30). Using the multitasking continuum (i.e., low / continuous multitasking = multiple tasks within seconds to minutes, high / sequential multitasking $=$ multiple tasks within minutes to hours), performing many activities per hour are located on the lower end of this spectrum (i.e., more continuous-like multitasking), while performing very few activities per hour are located on the higher end of this spectrum (i.e., sequential multitasking).

\section{Switching Behaviour (Exploration-Exploitation or Exploitation- Exploration Sequences)}

As a dependent variable, we calculated the likelihood of participants showing sequential switching behaviour. A sequential switch was captured when an entrepreneur switched from exploration to exploitation (and vice versa, i.e., exploitation-exploration). We counted these switches for each working hour $(M=2.05, S D=2.17)$, that is, on average entrepreneurs showed two behavioural switches (from exploration to exploitation, or vice versa) per hour. Furthermore, we obtained the likelihood of switching by dividing the number of these switches by the number of all behaviours that the entrepreneurs displayed in that time interval $(M=0.27, S D=0.27)$, that is, there was a $27 \%$ likelihood of a behavioural sequence to contain switches. To illustrate, an entrepreneur could have shown six behaviours within one hour (three exploration and three exploitation behaviours). If the behavioural sequence is xplor-xplor-xplor-xploixploi-xploi ${ }^{3}$, we would count 1 switching activity (and a likelihood of $16 \%$ (i.e., 1/6) to display switching), whereas for a sequence like xploi-xplor-xploi-xplor-xploi-xplor, we

\footnotetext{
${ }^{3}$ xplor $=$ exploration, xploi $=$ exploitation
} 
This is a post-print version ${ }^{1}$. This article may not exactly replicate the final version published in the journal. The final peer-reviewed and edited copy of this manuscript is available here:

https://doi.org/10.1177/0266242620943371

would count 5 switches (and a likelihood of $83 \%$ (i.e., 5/6) for switching). We did not use the mere frequency of switching behaviour since this variable is confounded with the number of activities that entrepreneurs could display in one hour (more activities within one hour would be associated with higher frequencies of switching behaviours).

\section{Within-person Measure of Ambidexterity}

To test hypothesis 3 and 4, we had to derive a continuous within-person measure of ambidexterity. To do this, we summarised coded exploration and exploitation behaviours for every hour, which resulted in 24 to 36 repeated measures of objective frequency for exploration $(M=1.55 ; S D=1.94)$ and exploitation $(M=6.91 ; S D=5.34)$ for each entrepreneur. For testing the association between paradoxical leadership and ambidexterity, we followed Mom et al.'s (2009) approach and operationalised ambidexterity by using the multiplicative interaction between exploration and exploitation scores.

\section{Paradoxical Leadership}

We measured paradoxical leadership based on the behavioural observations of the entrepreneurs using two types of paradoxical leadership behaviours (directive versus participative leadership). Directive leadership covered behaviours that provide clear directions and objectives "to ensure that work procedures are aligned with the organisation's vision and objectives” (Alfes and Langner, 2017: 99). Hence, giving directions to employees, monitoring work processes, organising and coordinating tasks were coded as directive leadership behaviours. Conversely, exchanging information, seeking opinions, maintaining relationships with others and networking were coded as participative leadership behaviours (see Table 2). Based on these behavioural observations, we used the frequency of participatory behaviours per hour $(M=4.75 ; S D$ $=3.75)$ and the frequency of directive behaviours per hour $(M=2.17 ; S D=2.34)$.

Paradoxical leadership was calculated as the multiplicative interaction between participatory and directive leadership scores for each working hour.

\section{Validity of Paradoxical Leadership Behaviours}

Validity of paradoxical leadership behaviours was also assessed using lexical content analyses (McKenny et al., 2013). We used lexical categories of LIWC that map onto theoretical features of paradoxical leadership, namely social processes ("communication," "reference to others"), and expressions of inclusion (e.g., "and," 
This is a post-print version ${ }^{1}$. This article may not exactly replicate the final version published in the journal. The final peer-reviewed and edited copy of this manuscript is available here:

https://doi.org/10.1177/0266242620943371

"with," "include") for participatory leadership behaviours. We used lexical categories that express command and control processes (inhibition, i.e., "block," "constrain," "stop" etc. and certainty, i.e. "always," "never") for directive leadership behaviours.

As expected, behaviours coded as participatory leadership contained higher levels of social processes $(M=14.76, S D=12.76)$, communication $(M=8.70, S D=$ $10.27)$, and reference to others $(M=0.83, S D=2.72)$ in comparison to behaviours coded as directive leadership (social: $M=8.2, S D=10.22, p<0.01$; communication: $M$ $=4.25, S D=7.01, p<0.01$; reference to others: $M=0.77, S D=2.64, p>0.05$ ).

Conversely, words that expressed command and control processes, that is, inhibition $(M$ $=0.35, S D=2.14)$ and certainty $(M=0.21, S D=1.28)$ were higher for directive leadership in comparison to participatory leadership (inhibition: $M=0.26, S D=1.59, p$ $=0.23$; certainty: $M=0.11, S D=0.86, p<0.01)$. Overall, these linguistic content analyses support the validity of the paradoxical leadership coding scheme.

\section{Firm Life Cycle Stage}

Based on the age of the company, each entrepreneur was categorised as either being in a start-up stage (i.e., business was in place for 12 months or less) or within a growth stage (i.e., business was in place for more than 12 months). This resulted in a dichotomous between-person variable (i.e., life cycle stage; with $0=$ start-up company stage and 1 = growth company stage).

Start-up and growth entrepreneurs differed significantly in terms of their number of employees (Start-up: $M=10.5$ employees, $S D=7.89$; Growth: $M=119$ employees, $S D=101.29, p<0.05)$ and turnover in $€($ Start-up: $M=0.16$ million, $S D=0.12$; Growth: $M=20.26$ million, $S D=18.13, p<0.10$ ) which also support the validity of the life cycle stage variable.

\section{Results}

\section{Sequential Analysis of Exploration and Exploitation}

$\mathrm{H} 1$ proposed that individual ambidexterity draws on self-sustaining cycles whereby exploration activities are followed by exploration activities. Conversely, exploitation activities are followed by exploitation activities. To test this hypothesis concerning sequential entrepreneurial activity patterns, we conducted sequential analysis (Bakeman and Quera, 2011; Klonek et al., 2016). The association between 
This is a post-print version ${ }^{1}$. This article may not exactly replicate the final version published in the journal. The final peer-reviewed and edited copy of this manuscript is available here:

https://doi.org/10.1177/0266242620943371

activities was analysed between a given activity ( $\operatorname{lag} 0)$ and the immediately following activity (lag1). This allowed us to systematically test sequential behavioural associations of entrepreneurial exploration and exploitation over time. Based on the sequence of 4,355 observations, we generated lag-sequential matrices containing joint frequencies for adjacent activities. Lagged joint frequencies and lagged conditional probabilities (i.e., the probability that the activity occurred when preceded by a particular event) were compared to the baseline (i.e., unconditional) probability for each activity.

Using the General Sequential Querier (Bakeman and Quera, 2011), a statistical program for sequential analyses, we produced a lagged matrix with both exploration and exploitation behaviour at lag0 (given activity) and exploration and exploitation behaviour at lag1 (following activity).

Preceding activities are in rows (lag0), whereas subsequent activities are in columns (lag1). For example, the probability of an exploration activity, given that the previous activity was exploration, is $P\left({\text { Explore }{ }_{\text {lag }} \mid} \mid\right.$ Explore $\left._{\text {lag } I}\right)=0.34$. This means that the conditional probability of exploration when preceded by an exploratory activity is 34 percent, while the baseline probability of exploration is $P($ Explore $)=0.18$ (i.e., 18 $\%)$. We also calculated adjusted residuals for each cell, that is, standardised raw residuals based on the difference between the observed and expected frequency, to test for significance.

Hypothesis 1 predicted self-sustaining activity cycles (i.e., exploration sustaining exploration; exploitation sustaining exploitation). In support of hypothesis 1, exploitation was more likely to emerge when preceded by exploitation $\left(P\left(\right.\right.$ Exploit $l a g 0 \mid$ Exploit $\left.\left.l a g l_{1}\right)=0.85\right)$ in comparison to the unconditional probability $(P($ Exploit $)=0.82, p<0.01)$. Furthermore, exploration was more likely to emerge when

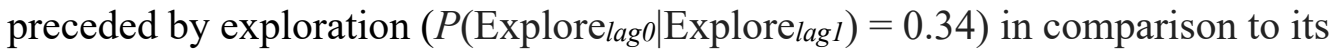
unconditional probability $(P($ Explore $)=0.18, p<0.01)$. These results support hypothesis 1 , which predicted self-sustaining cycles. Figure 1 summarises the results of the sequential analyses using a state transition diagram.

++++Insert Figure 1 here++++

\section{Multitasking and Behavioural Switching}


This is a post-print version ${ }^{1}$. This article may not exactly replicate the final version published in the journal. The final peer-reviewed and edited copy of this manuscript is available here:

https://doi.org/10.1177/0266242620943371

$\mathrm{H} 2$ proposed that multitasking is negatively related with behavioural switching between exploration and exploitation behaviours. First, we investigated associations on the hourly level of analyses. The measure of multitasking showed a significant negative correlation with the likelihood of ambidextrous switching $(r=-.19, p<0.01)$ and a significant negative correlation with the likelihood to engage in exploration activities ( $r$ $=-.24, p<0.01)$. To control for the nested data, we dummy-coded for entrepreneurs as fixed effects (Antonakis et al., 2010), that is, we used $11(\mathrm{k}-1)$ dummy or indicator variables, with $k$ representing each entrepreneur (McNeish and Stapleton, 2016) and ran multiple linear regressions. Using fixed effects modelling has the advantage that it requires fewer assumptions than multi-level modelling and the estimates for the dummy variables have the advantage that the cluster affiliation variables account for all heterogeneity at the person-level, which reduces concerns about omitted variable bias at Level 2 (McNeish and Stapleton, 2016). We entered variables in two steps to predict the likelihood of behavioural switching. First, we entered dummy variables (i.e., entrepreneurs as fixed effects) $\left(F(11,372)=10.46, p<0.01, \mathrm{R}^{2}=0.23\right)$. Second, we entered multitasking $\left(\Delta F(1,371)=18.08, p<0.01, \Delta \mathrm{R}^{2}=0.029\right)$, that is, multitasking significantly reduced the likelihood of behavioural switching $(\mathrm{B}=-0.052, \mathrm{SD}=0.014, p$ $<0.01)$. Overall, these results supported Hypothesis 2 .

\section{The Relationship Between Paradoxical Leadership and Ambidexterity}

Table 3 shows descriptive statistics and correlations matrix.

$$
\text { ++++Insert Table } 3 \text { here++++ }
$$

To test how the relationship between paradoxical leadership and individual ambidexterity is moderated by the firm life cycle (Hypothesis 3), we ran hierarchical linear models (HLM; Raudenbush, Bryk and Congdon, 2004). The level 1 outcome and predictor variables were within-person variations of individual ambidexterity and paradoxical leadership. Entrepreneurial stage was used as a between-person (level 2) variable and was effect coded (i.e., start-up firm $=0$; growth firm=1). We first ran a baseline, or "null" model to determine the percentage of variance in ambidexterity that resided within and between entrepreneurs (cf., Aguinis, Gottfredson and Culpepper, 2013): $15.5 \%$ of ambidexterity variance resided at the between-person level, and $84.5 \%$ 
This is a post-print version ${ }^{1}$. This article may not exactly replicate the final version published in the journal. The final peer-reviewed and edited copy of this manuscript is available here:

https://doi.org/10.1177/0266242620943371

of the variance resided at the within-person level (Hofmann, Griffin and Gavin, 2000), suggesting that the HLM was appropriate.

Hypothesis 3 stated that paradoxical leadership is positively associated with individual ambidexterity. To test this hypothesis, we estimated a random intercept and fixed slope model and included three group-mean centred within-person predictors (participatory, directive, and paradoxical leadership) and one between-person predictor (i.e., entrepreneurial stage). In support of Hypothesis 3, within-person fluctuations of paradoxical leadership in the model were positively associated with within-person fluctuations of ambidexterity $\left(\beta_{30}=0.13, p<0.10\right)$.

Hypothesis 4 stated that the firms life cycle moderates the relationship between paradoxical leadership behaviours and ambidexterity, such that this relationship is stronger in the start-up firms and weaker in the growth firms. To test this hypothesis, we ran a random intercept and random slope model using entrepreneurial stage as a between-person cross-level predictor based on the following formula:

Level-1: Ambidexterity ${ }_{\mathrm{ij}}=\beta_{01}+\beta_{10}($ Directive Leadership $)+\beta_{20}($ Participative Leadership $)+\beta 30($ Paradoxical Leadership $)+e$

Level-2: $\beta_{01}=\beta_{00}+\beta_{01}($ Stage $)+r_{0}$

Level-2: $\beta_{30}=\beta_{30}+\beta_{31}($ Stage $)+r_{3}$

$$
++++ \text { Insert Table } 4 \text { here }++++
$$

In support of Hypothesis 4, the cross-level interaction term of the life cycle stage (between-person variable) in the random intercepts and random slopes model significantly predicted within-person changes of individual ambidexterity $\left(\beta_{31}=-0.28\right.$, $\mathrm{p}<0.05)$. This means that paradoxical leadership and individual ambidexterity are associated in start-up stage companies, whereas this association becomes weaker for growth companies. We graphed this moderation in Figure 2.

$$
++++ \text { Insert Figure } 2 \text { here }++++
$$

\section{Discussion}

Our study has provided three important results. First, our study has implications for a better theoretical understanding of how entrepreneurs manage ambidexterity via temporal sequencing of exploration and exploitation behaviours. We extended the emergent stream of research on individual ambidexterity by providing an insight into 
This is a post-print version ${ }^{1}$. This article may not exactly replicate the final version published in the journal. The final peer-reviewed and edited copy of this manuscript is available here:

https://doi.org/10.1177/0266242620943371

the dynamic self-regulation of exploration and exploitation activities in entrepreneurs.

Second, our research indicates that multitasking behaviours further reduce the likelihood of switching between exploration and exploitation tasks. Third, our research sheds light on the complex relationship between entrepreneurial ambidexterity and paradoxical leadership - in particular, we show that this relationship is contingent on the firm life cycle stage.

With respect to our first finding, ambidexterity is a temporally dynamic and emerging construct that can manifest in micro-level temporal activities (Rosing and Zacher, 2017). Yet, extant research has adopted a between-person analytical approach (e.g., Kaupilla and Tempelaar, 2016; Keller and Weibler, 2015; Mom et al., 2009) that has treated individual ambidexterity as a static and time-invariant construct. Hence, previous research has not fully unpacked how exploration and exploitation activities are temporally sequenced over time. Furthermore, the research stream has not studied the person-level ambidexterity in entrepreneurs. Studying temporal dynamics of ambidextrous behaviours in entrepreneurs is important because they exert a significant influence on their business venture. Our results expand knowledge on the microdynamic temporal fluctuations of individual exploration and exploitation, which has proposed that switching between activities is associated with negative affective reactions and behavioural switching resistance (Bidmon and Boe-Lillegraven, 2019).

While the study from Bidmon and Boe-Lillegraven (2019) has been valuable in proposing an initial theoretical understanding of what happens during switching, it has been limited in three important ways. First, the study was focused on explicit switching requests and, it is unclear whether similar response patterns would occur during natural switching. Second, the research from Bidmon and Boe-Lillegraven (2019) has studied switching behaviour in a small sample of employees during a workshop activity, and we do not know whether similar response patterns would occur in entrepreneurs whilst working "in their natural habitat". Third, while the qualitative nature of the study has provided an initial framework to propose what happens around switching, a quantitative empirical test of these proposed relationships has still been lacking. In this respect, our study has significantly expanded the previous research by showing that entrepreneurs exhibited patterns of self-sustaining cycles in which exploration sustained further exploration, and exploitation sustained further exploitation. Overall, exploration and 
This is a post-print version ${ }^{1}$. This article may not exactly replicate the final version published in the journal. The final peer-reviewed and edited copy of this manuscript is available here:

https://doi.org/10.1177/0266242620943371

exploitation showed a self-sustaining tendency. While ambidexterity is required to host contradictions in dealing with exploration and exploitation, there are limits on how entrepreneurs can accommodate the coexistence of both behaviours. Managing contradictory demands of exploration and exploitation constitute a practical challenge, and as Cunha et al. (2019: 716) pointed out, individuals need to choose "one pole over the other, rather than other possibilities to handle paradoxical demands in a sustainable and persisting way." This also strengthens the view of exploration and exploitation as the two ends of a unidimensional scale (March, 1991).

With respect to our second finding, our analyses suggests that multitasking behaviours reduce the likelihood of switching between exploration and exploitation activities. In other words, when entrepreneurs showed a high level of multitasking, entrepreneurs were more likely to sustain their activity pattern. This finding also contributes knowledge to the very limited literature on multitasking in the workplace (Kirchberg et al., 2015; König et al, 2010). While there is relatively rich literature on the parallel cognitive mechanisms that underly simultaneous multitasking, the study of multitasking over longer time periods across the workday has been less explored (König et al., 2010) and only focused on non-entrepreneurial populations. While diary studies on multitasking behaviour have shown that it is negatively associated with performance and productivity, our research further expands this knowledge by showing how multitasking also harms entrepreneurs' capacity to engage in ambidextrous switching.

With respect to our third finding, our study clarifies the relationship between individual ambidexterity and paradoxical leadership. Even though ambidexterity and paradoxical leadership have different conceptual definitions, these terms have been used somehow interchangeably in the literature (Rosing, Frese and Bausch, 2011). Our study clarifies this literature by studying both constructs within the same individuals. Our results suggest that individual ambidexterity and paradoxical leadership are enabled through a similar set of antecedents since they were positively associated. This positive association was further contingent on the firm life cycle in which entrepreneurs operated. While ambidexterity and paradoxical leadership were strongly associated in the start-up stage of the life cycle, the association became weaker for entrepreneurs who operated in the growth stage of business.

\section{Practical Implications}


This is a post-print version ${ }^{1}$. This article may not exactly replicate the final version published in the journal. The final peer-reviewed and edited copy of this manuscript is available here:

https://doi.org/10.1177/0266242620943371

In terms of practical implications, our study showed that exploration and exploitation are self-sustaining activities. For example, an entrepreneur tends to engage in a sustained set of exploitation behaviours (e.g., serving existing clients, improving the production costs for a product) or a sustained set of explorative behaviours (e.g., exploring new client groups, developing a new product), rather than rapidly switching from one type of activity to the other within a short time. Hence, it is important to translate these findings for entrepreneurs who would like to achieve higher levels of ambidexterity. They could learn from our study that their exploration activities (and also exploitation) are self-enhancing and that entrepreneurs may easily become trapped in self-sustaining cycles. Furthermore, it is important to point out that multitasking behaviour is not necessarily conducive to increasing ambidextrous switching.

Our research also supports the argument that integration of paradoxical activities is harder to achieve within individuals than it is within organisations (Caniëls and Veld, 2019). As Gupta et al. (2006: 696) pointed out, "with division of labour and allocation of resources, it may be easier for a group, organisation, or larger system to simultaneously excel at exploration and exploitation than it is for individuals to do so."

In addition, our study showed that the positive association between individual ambidexterity and paradoxical leadership disappeared when entrepreneurs operated within growth stages of the company. Practically, this implies that a successful transition from a start-up to a growth business requires that entrepreneurs learn to develop a more nuanced and complex behavioural repertoire in which leading others is a separate and distinct activity relative to their own entrepreneurial ambidexterity. By adopting a paradoxical leadership style, that is, a social influence strategy that enables employees to both explore and exploit, entrepreneurs can direct ambidextrous behaviours of their employees (Kaupilla and Tempelaar, 2016). This way, successful entrepreneurs can enrich the jobs of their workforce and simultaneously create an ambidextrous organisation (Parker, 2014).

\section{Limitations and Future Research}

This study has the following limitations. First, the overall sample of entrepreneurs studied is limited. Since the main aim of the study was to examine withinperson associations of exploration-exploitation as well as the intra-personal associations between ambidexterity and paradoxical leadership, this limitation is not a major concern 
This is a post-print version ${ }^{1}$. This article may not exactly replicate the final version published in the journal. The final peer-reviewed and edited copy of this manuscript is available here:

https://doi.org/10.1177/0266242620943371

with respect to our research questions. Nevertheless, with respect to the cross-level effect of individual variables (e.g., entrepreneurial stage) on within-person associations, we encourage future studies to expand this research using larger samples of entrepreneurs. Future research should also focus on different populations, such as unsuccessful entrepreneurs, employees and/or managers to investigate whether these individuals show different sequential patterns of exploitation and exploration behaviours. We would assume that the typical day of an entrepreneur may look very different to a typical day of employees and of managers and future research could shed light on these differential patterns.

Second, the firm life cycle stage was studied as a between-person variable. However, a more rigorous design should observe different life cycle stages within the same entrepreneurs. Unfortunately, this study design would require very complex and expensive (i.e., time-intensive) longitudinal designs in which exploration and exploitation of the same entrepreneurs are continuously monitored within shorter time frames (e.g., days or weeks) but also intermittently over extended time frames (e.g., months or years).

Third, it would be interesting to know whether successful in contrast to unsuccessful entrepreneurs show different sequential patterns of exploration and exploitation activities. For example, we would assume that entrepreneurs who show many (in contrast to few) switches between exploration and exploitation are better in integrating potential synergies that both activities produce and show higher innovative performance. However, we did not have access to a comparison group of unsuccessful entrepreneurs, which would have allowed us to answer this question.

Fourth, we did not explicitly capture cognitive variables in our research design, which we assumed to be a mechanism for the self-sustaining cycles. Hence, we would encourage future research to measure cognitive variables when studying the sequential switching between exploration and exploitation in entrepreneurs in order to explore this assumed mechanism. A comprehensive conceptual model that specifies antecedents and consequences of individual ambidexterity is still lacking. Theory development should not only focus on individual antecedents (e.g., cognitive flexibility), but situational antecedents that could also play a crucial role in enhancing switches from exploration to exploitation. This research can provide an in-depth understanding of the cognitive 
This is a post-print version ${ }^{1}$. This article may not exactly replicate the final version published in the journal. The final peer-reviewed and edited copy of this manuscript is available here:

https://doi.org/10.1177/0266242620943371

mechanism for how entrepreneurs manage exploration and exploitation beyond the prescription to embrace two conflicting behaviours. In this sense, our study has opened up new research questions that might also require new methodological approaches. We encourage future research on these activities which may be affected by both situational variables and individual variables such as cognitive flexibility (Keller and Weibler, 2015).

Fifth, our measures of paradoxical leadership and exploration-exploitation were both based on coded observations from third-party observers. Essentially, this constitutes a common-method bias, that is, variance could be related "to the measurement method rather than to the constructs the measures represent" (Podsakoff et al., 2003: 879). Common-method bias has been extensively discussed in research that uses cross-sectional and self-report (i.e., focal respondent) multi-item rating scales. However, many potential sources of common-rater biases that were identified by Podsakoff et al. (2003), such as item characteristic effects (item social desirability, scale length, format and anchors) can be considered as having minimal (or no) influence in our research design since we did not capture ratings of these variables from the entrepreneurs but from external observers who had no motivation to provide socially desirable ratings (in contrast to focal participants who provide self-reports on a scale). Furthermore, we also used no items with similar scale lengths, format, or anchors etc. but coded observations into discrete categories and then aggregated these observations into summary indices. Finally, we followed recommendations from Podsdakoff et al. (2003) to further reduce common-method bias and temporally separated the coding of exploration/exploitation behaviours from the leadership behaviours (i.e., our observers coded these focal constructs at different times).

Sixth, in our analytical approach, we have coded each activity exclusively as either exploration or as exploitation. In other words, we used a dichotomy of exploration-versus-exploitation for each single behaviour. However, it could be argued that some activities could contain elements of both exploration and exploitation. For example, discussions on hiring staff could be seen both as exploratory but also as exploitative. Therefore, we would encourage future research to adopt more nuanced approaches in which activities are not only coded dichotomously but instead researchers 
This is a post-print version ${ }^{1}$. This article may not exactly replicate the final version published in the journal. The final peer-reviewed and edited copy of this manuscript is available here:

https://doi.org/10.1177/0266242620943371

could also use a bi-polar ambidexterity scale with the two extremes of exploration versus exploitation.

Seventh, our study relied on a shadowing approach to capture how the entrepreneurs sequenced exploration and exploitation activities. One limitation is that we cannot rule out entirely that the presence of observers may have an influence on the entrepreneurial behaviour (i.e., being both conscious about the observer and displaying more conscientious behaviours). However, we tried to minimise the potential observation effect by taking multiple preventive measures. First, all observers proactively engaged with the entrepreneurs ahead of time of the actual shadowing period, which helped in building trust and allowing the entrepreneurs to feel familiar with the observer (so that they would not exhibit artificial behaviour). Furthermore, the observers took particular care to be as unobtrusive as possible (i.e. being "the fly on the wall") and entrepreneurs became often unaware of the observer's presence (e.g., they would talk about private issues on the phone).

\section{Conclusion}

For entrepreneurs, balancing ambidextrous activity constitutes a dynamic and time-sensitive phenomenon. We focused on intra-individual fluctuations of individual ambidexterity using a novel methodological approach that has helped to unpack the temporal patterns of exploration and exploitation activities. Our study contributes to a better understanding of the temporal nature of individual ambidexterity by demonstrating that successful entrepreneurs show self-sustaining tendencies. Furthermore, when comparing companies across different life cycle stages, our study indicates a dissociation of entrepreneurial ambidexterity and paradoxical leadership for growth stage companies. 
This is a post-print version ${ }^{1}$. This article may not exactly replicate the final version published in the journal. The final peer-reviewed and edited copy of this manuscript is available here:

\section{References}

Adler RF and Benbunan-Fich R (2012) Juggling on a high wire: Multitasking effects on performance. International Journal of Human-Computer Studies, 70, 156-168. doi:10.1016/j.ijhcs.2011.10.003

Adler RF and Benbunan-Fich R (2013) Self-interruptions in discretionary multitasking. Computers in Human Behavior, 29, 1441-1449. doi:10.1016/j.chb.2013.01.040

Aguinis H, Gottfredson RK and Culpepper SA (2013) Best-practice recommendations for estimating cross-level interaction effects using multilevel modeling. Journal of Management 39: 1490-1528.

Ahmadi S, Khanagha S, Berchicci L and Jansen JJ (2017) Are managers motivated to explore in the face of a new technological change? The role of regulatory focus, fit, and complexity of decision-making. Journal of Management Studies, 54: 209-237.

Alfes K and Langner N (2017) Paradoxical leadership: understanding and managing conflicting tensions to foster volunteer engagement. Organisational Dynamics 46: 96-103.

Althoff T, Salehi N and Nguyen T (2013) Random acts of pizza: Success factors of online requests. Stanford: Department of Computer Science.

Antonakis J, Bendahan S, Jacquart P and Lalive R (2010) On making causal claims: A review and recommendations. The Leadership Quarterly 21: 1086-1120.

Bakeman R and Quera V (2011) Sequential Analysis and Observational Methods for the Behavioural Sciences. Cambridge: Cambridge University Press.

Bidmon CM and Boe-Lillegraven S (2019) Now, switch! Individuals' responses to imposed switches between exploration and exploitation. Long Range Planning. Advanced online publication. 101928. https://doi.org/10.1016/j.lrp.2019.101928

Bird BJ and Schjoedt L (2009) Entrepreneurial behaviour: Its nature, scope, recent research, and agenda for future research. In: Carsrud AL and Brännback M (eds), Understanding the entrepreneurial mind, international studies in entrepreneurship. New York: Springer Science and Business Media, LLC, pp.327-358. 
This is a post-print version ${ }^{1}$. This article may not exactly replicate the final version published in the journal. The final peer-reviewed and edited copy of this manuscript is available here:

https://doi.org/10.1177/0266242620943371

Bledow R, Frese M, Anderson N, Erez M and Farr J (2009) A dialectic perspective on innovation: Conflicting demands, multiple pathways, and ambidexterity. Industrial and Organizational Psychology 2: 305-337.

Bonesso S, Gerli F and Scapolan A (2014) The individual side of ambidexterity: Do individuals' perceptions match actual behaviors in reconciling the exploration and exploitation trade-off? European Management Journal 32: 392-405.

Buser T and Peter N (2012) Multitasking. Experimental Economics, 15, 641-655. doi:10.1007/s10683-012-9318-8

Caniëls MC and Veld M (2019) Employee ambidexterity, high performance work systems and innovative work behaviour: How much balance do we need? The International Journal of Human Resource Management 30: 565-585.

Chan HF, Moy N, Schaffner M and Torgler B (2019) The effects of money saliency and sustainability orientation on reward based crowdfunding success. Journal of Business Research. Advanced online publication: https://doi.org/10.1016/j.jbusres.2019.07.037

Chang Y-C, Yang PY, Martin BR, Chi H-R and Tsai-Lin T-F (2016) Entrepreneurial universities and research ambidexterity: A multilevel analysis. Technovation, 54: 7-21. doi:10.1016/j.technovation.2016.02.006

Chen G, Crossland C and Luo S (2015) Making the same mistake all over again: CEO overconfidence and corporate resistance to corrective feedback. Strategic Management Journal 36: 1513-1535.

Cogliser CC and Brigham KH (2004) The intersection of leadership and entrepreneurship: mutual lessons to be learned. The Leadership Quarterly 15: 771-799.

Cunha MPE, Fortes A, Gomes, E, Rego A and Rodrigues F (2019) Ambidextrous leadership, paradox and contingency: evidence from Angola. The International Journal of Human Resource Management, 30: 702-727.

Dheer R and Lenartowicz T (2017) Cognitive flexibility: Impact on efficacy and intentions towards entrepreneurship. In: Academy of Management Annual Meeting Proceedings 2017, Atlanta, USA, 4-8 August 2017, pp. 11567. New York: Academy of Management. 
This is a post-print version ${ }^{1}$. This article may not exactly replicate the final version published in the journal. The final peer-reviewed and edited copy of this manuscript is available here:

https://doi.org/10.1177/0266242620943371

Eisenhardt KM, Furr NR and Bingham CB (2010) CROSSROADS-Microfoundations of performance: Balancing efficiency and flexibility in dynamic environments. Organisation Science 21: 1263-1273.

Gebert D, Boerner S and Kearney E (2010) Fostering team innovation: Why is it important to combine opposing action strategies? Organisation Science 21: 593-608.

Good D and Michel EJ (2013) Individual ambidexterity: Exploring and exploiting in dynamic contexts. The Journal of Psychology 147: 435-453.

Gorgievski MJ and Stephan U (2016) Advancing the psychology of entrepreneurship: A review of the psychological literature and an introduction. Applied Psychology, 65: 437-468.

Gupta AK, Smith KG and Shalley CE (2006) The interplay between exploration and exploitation. Academy of Management Journal 49: 693-706.

Håkonsson DD, Eskildsen JK, Argote L, Mønster D, Burton RM and Obel B (2016) Exploration versus exploitation: Emotions and performance as antecedents and consequences of team decisions. Strategic Management Journal, 6: 985-1001.

Hanks SH and Chandler G (1994) Patterns of functional specialization in emerging high-tech firms. Journal of Small Business Management 32: 23-36.

Hansen NK, Güttel WH and Swart J (2019) HRM in dynamic environments: Exploitative, exploratory, and ambidextrous HR architectures. The International Journal of Human Resource Management 30: 648-679.

Hofmann DA, Griffin MA and Gavin MB (2000) The application of hierarchical linear modeling to organizational research. In: Klein K and Kozlowski SWJ (eds) Multilevel Theory, Research, and Methods in Organizations. San Francisco, CA: Jossey-Bass, 423-468.

Junni P, Sarala RM, Taras V and Tarba SY (2013) Organizational ambidexterity and performance: A meta-analysis. Academy of Management Perspectives 27: 299312.

Kauppila OP and Tempelaar MP (2016) The social-cognitive underpinnings of employees' ambidextrous behaviour and the supportive role of group managers' leadership. Journal of Management Studies 53: 1019-1044. 
This is a post-print version ${ }^{1}$. This article may not exactly replicate the final version published in the journal. The final peer-reviewed and edited copy of this manuscript is available here:

https://doi.org/10.1177/0266242620943371

Kazanjian RK and Drazin R (1990) A stage-contingent model of design and growth for technology based new ventures. Journal of Business Venturing 5: 137-150.

Keller T and Weibler J (2015) What it takes and costs to be an ambidextrous manager:

Linking leadership and cognitive strain to balancing exploration and exploitation. Journal of Leadership and Organizational Studies 22: 54-71.

Kirchberg, DM, Roe, RA, and Van Eerde, W (2015) Polychronicity and multitasking: A diary study at work. Human Performance, 28: 112-136.

Klonek F, Quera V, Burba M and Kauffeld S (2016) Group interactions and time: Using sequential analysis to study group dynamics in project meetings. Group Dynamics: Theory, Research, and Practice 20: 209-222.

Kobarg S, Wollersheim J, Welpe IM and Spörrle M (2017) Individual ambidexterity and performance in the public sector: a multilevel analysis. International Public Management Journal 20: 226-260.

Koryak O, Mole KF, Lockett A, Hayton JC, Ucbasaran D and Hodgkinson GP (2015) Entrepreneurial leadership, capabilities and firm growth. International Small Business Journal 33: 89-105.

König CJ, Oberacher, L, and Kleinmann, M. (2010) Personal and situational determinants of multitasking at work. Journal of Personnel Psychology

Laureiro-Martínez D, Brusoni S and Zollo M (2010) The neuroscientific foundations of the exploration-exploitation dilemma. Journal of Neuroscience, Psychology, and Economics 3: 95-115.

Lavie D, Stettner U, Tushman ML (2010) Exploration and exploitation within and across organisations. Academy of Management Annals 4: 109-155.

Leitch CM and Volery T (2017) Entrepreneurial leadership: Insights and directions. International Small Business Journal 35: 147-156.

Lester DL, Parnell JA and Carraher S (2003) Organisational life cycle: a five-stage empirical scale. The International Journal of Organisational Analysis, 11: 339354.

McKenny A, Short J and Payne G (2013) Using computer-aided text analysis to elevate constructs: An illustration using psychological capital. Organisational Research Methods 16: 152-184. 
This is a post-print version ${ }^{1}$. This article may not exactly replicate the final version published in the journal. The final peer-reviewed and edited copy of this manuscript is available here:

https://doi.org/10.1177/0266242620943371

McNeish D and Stapleton LM (2016) Modeling clustered data with very few clusters. Multivariate Behavioral Research 51: 495-518.

March JG (1991) Exploration and exploitation in organisational learning. Organisation Science 2: 71-87.

Mathias B, Mckenny A and Crook T (2018) Managing the tensions between exploration and exploitation: The role of time. Strategic Entrepreneurship Journal, 12: 316 334.

Mintzberg H (1973) The Nature of Managerial Work. New York: Harper and Row.

Mom TJ, Van Den Bosch FA and Volberda HW (2009) Understanding variation in managers' ambidexterity: investigating direct and interaction effects of formal structural and personal coordination mechanisms. Organisation Science 20: $812-828$.

Monsell S (2003) Task switching. Trends in Cognitive Sciences 7: 134-140. doi:10.1016/s1364-6613(03)00028-7

Mu T, van Riel A and Schouteten R (2020) Individual ambidexterity in SMEs: Towards a typology aligning the concept, antecedents and outcomes. Journal of Small Business Management: 1-32.

Nagarajan M, Baid K, Sheth A and Wang S (2009) Monetizing user activity on social networks-challenges and experiences. In: Proceedings of the 2009 IEEE/WIC/ACM International Joint Conference on Web Intelligence and Intelligent Agent Technology, Milano, Italy September 2009, pp. $92-$ 99.Washington: IEEE Computer Society.

Newtson D (1973) Attribution and the unit of perception of ongoing behaviour. Journal of Personality and Social Psychology 28: 28-38.

Pashler H (2000) Task switching and multitask performance. In S. Monsell \& J. Driver (Eds.), Attention and performance XVIII: Control of mental processes (pp. 277-307). Cambridge, MA: MIT Press

Parker SK (2014) Beyond motivation: Job and work design for development, health, ambidexterity, and more. Annual Review of Psychology 65: 661-691.

Podsakoff, PM, MacKenzie, SB, Lee, JY, and Podsakoff, NP (2003) Common method biases in behavioral research: a critical review of the literature and recommended remedies. Journal of Applied Psychology, 88: 879 -903. 
This is a post-print version ${ }^{1}$. This article may not exactly replicate the final version published in the journal. The final peer-reviewed and edited copy of this manuscript is available here:

https://doi.org/10.1177/0266242620943371

Raudenbush SW, Bryk AS and Congdon R (2004) HLM 6 for Windows (Computer Software). Lincolnwood: Scientific Software International.

Rahman MM, Majumder MTH, Mukta MSH, Ali ME and Mahmud J (2016)

Can we predict eat-out preference of a person from tweets? In: Proceedings of the 8th ACM Conference on Web Science, Hannover, Germany, May 2016, pp. 350-351. New York: Association for Computing Machinery.

Renko M, El Tarabishy A, Carsrud AL and Brännback M (2015) Understanding and measuring entrepreneurial leadership style. Journal of Small Business Management, 53: 54-74.

Rosing K, Frese M and Bausch A (2011) Explaining the heterogeneity of the leadership-innovation relationship: Ambidextrous leadership. The Leadership Quarterly 22: 956-974.

Rosing K and Zacher H (2017) Individual ambidexterity: The duality of exploration and exploitation and its relationship with innovative performance. European Journal of Work and Organisational Psychology 26: 694-709.

Salvucci DD and Taatgen NA (2008) Threaded cognition: An integrated theory of concurrent multitasking. Psychological Review, 115: 101.

Salvucci DD, Taatgen NA and Borst JP (2009, April) Toward a unified theory of the multitasking continuum: From concurrent performance to task switching, interruption, and resumption. In Proceedings of the SIGCHI conference on human factors in computing systems (pp. 1819-1828).

Sanderson, KR, Bruk-Lee, V, Viswesvaran, C, Gutierrez, S, and Kantrowitz, T (2013) Multitasking: Do preference and ability interact to predict performance at work? Journal of occupational and organizational psychology, 86: 556-563.

Schad J, Lewis MW, Raisch S and Smith WK (2016) Paradox research in management science: Looking back to move forward. The Academy of Management Annals, 10: 5-64.

Shane S and Venkataraman S (2000) The promise of entrepreneurship as a field of research. Academy of Management Review 25: 217-226.

Shipp A, Edwards JR and Lambert LS (2009) Conceptualization and measurement of temporal focus: the subjective experience of the past, present, and future. Organisational Behavior and Human Decision Processes 110(1): 1-22. 
This is a post-print version ${ }^{1}$. This article may not exactly replicate the final version published in the journal. The final peer-reviewed and edited copy of this manuscript is available here:

https://doi.org/10.1177/0266242620943371

Sirmon DG, Hitt MA, Ireland RD and Gilbert BA (2011) Resource orchestration to create competitive advantage: Breadth, depth, and life cycle effects. Journal of Management 37: 1390-1412.

Smith WK and Lewis MW (2011) Toward a theory of paradox: A dynamic equilibrium model of organizing. Academy of Management Review, 36: 381-403.

Tausczik YR and Pennebaker JW (2010) The psychological meaning of words: LIWC and computerized text analysis methods. Journal of Language and Social Psychology 29: 24-54.

Tuncdogan A and Dogan IC (2019) Managers' regulatory focus, temporal focus and exploration-exploitation activities. Journal of Managerial Psychology.

Uy MA, Foo MD and Aguinis H (2010) Using experience sampling methodology to advance entrepreneurship theory and research. Organisational Research Methods 13: 31-54.

Van Praag CM and Versloot PH (2008) The economic benefits and costs of entrepreneurship: A review of the research. Foundations and Trends in Entrepreneurship, 4: 65-154. doi:10.1561/0300000012.

Wang M, Beal DJ, Chan D, Newman DA, Vancouver JB and Vandenberg RJ (2017) Longitudinal research: A panel discussion on conceptual issues, research design, and statistical techniques. Work, Aging and Retirement 3: $1-24$.

Wolf M, Horn A, Mehl M, Haug S, Pennebaker JW and Kordy H (2008) Computeraided quantitative text analysis: Equivalence and reliability of the German adaptation of the Linguistic Inquiry and Word Count. Diagnostica 54: 85-98.

Yeganegi S, Laplume AO, Dass P and Greidanus NS (2019) Individual-level ambidexterity and entrepreneurial entry. Journal of Small Business Management, 57: 1444-1463.

Zacher H, Robinson AJ and Rosing K (2016) Ambidextrous leadership and employees' self-reported innovative performance: The role of exploration and exploitation behaviours. The Journal of Creative Behaviour 50: 24-46. 


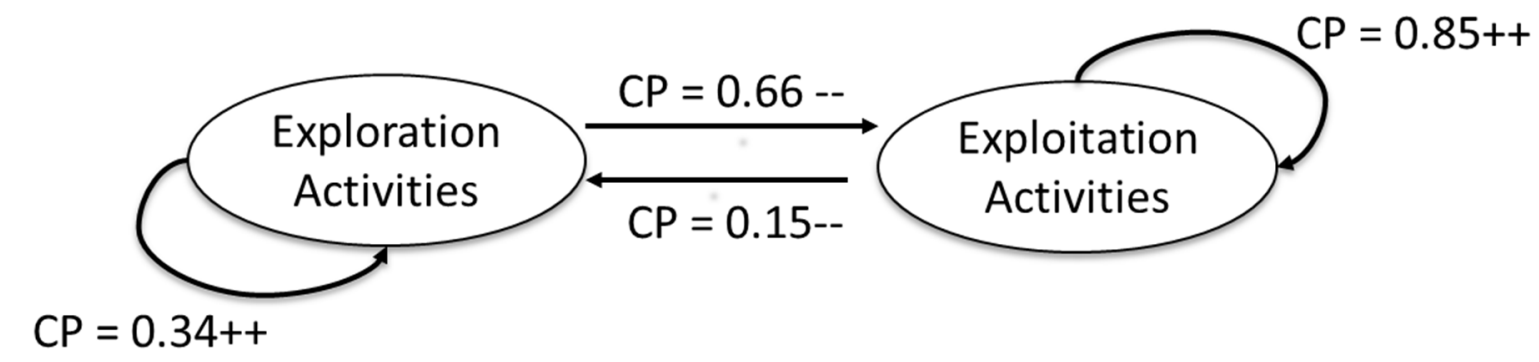

Figure 1. State transition diagram for the exploration and exploitation activities. The arrows from one activity to itself represent probabilities from a state to itself. $(++)$ more probable than expected by chance, $p<0.01 ;(--)$ less probable than expected by change, $p<0.01$. 
This is a post-print version ${ }^{1}$. This article may not exactly replicate the final version published in the journal. The final peer-reviewed and edited copy of this manuscript is available here:

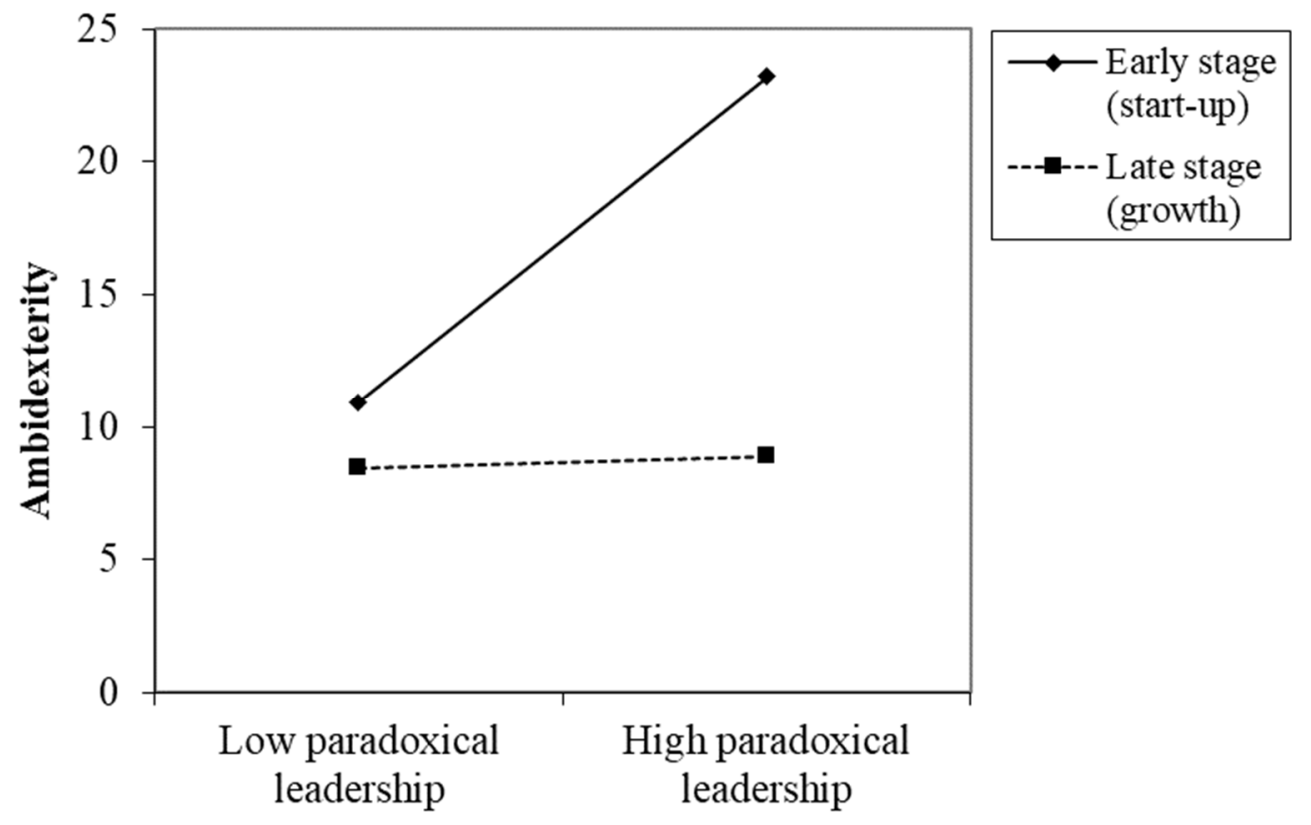

Figure 2. Cross-level effect of firm life cycle stage on the within-person association between paradoxical leadership and ambidexterity in successful entrepreneurs. 


\section{Table 1}

Sample characteristics

Entrepreneurs and industry in which

they operate

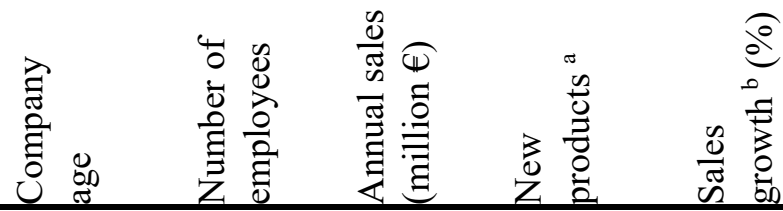

\begin{tabular}{lccccc}
\hline Entrepreneurs in start-ups & & & & & \\
\hline E-commerce & 5 months & 9 & 0.2 & 1 & n.a \\
\hline Catering & 3 months & 23 & n.a. & 2 & n.a \\
\hline Mobile advertising & 7 months & 17 & 0.3 & 2 & n.a. \\
\hline Thermoelectric generators & 12 months & 7 & 0.2 & 1 & n.a. \\
\hline Insurance services & 4 months & 3 & 0.1 & 1 & n.a. \\
\hline Medical technology & 8 months & 4 & 0 & 2 & n.a. \\
\hline
\end{tabular}

Entrepreneurs in established, growth-oriented ventures

\begin{tabular}{lccccc}
\hline Internet services & 8 years & 165 & 47 & 6 & 15 \\
\hline Pharmacy, retail & 5 years & 20 & 2.5 & 15 & 16 \\
\hline Software & 9 years & 65 & n.a. & 5 & 8 \\
\hline Robotic rehabilitation & 9 years & 104 & 21 & 5 & 22 \\
\hline Fencing franchise & 10 years & 300 & 26 & 3 & 27 \\
\hline Clean technology & 5 years & 60 & 4.8 & 3 & 59 \\
\hline
\end{tabular}

${ }^{a}$ Number of new products launched in the last 4 years

${ }^{\mathrm{b}}$ Average sales growth past 4 years 
Table 2

Systematic coding of ambidexterity and paradoxical leadership

\begin{tabular}{|c|c|c|c|c|c|c|}
\hline ID & Date & $\begin{array}{l}\text { Starting } \\
\text { time }\end{array}$ & $\begin{array}{l}\text { End } \\
\text { time }\end{array}$ & $\begin{array}{l}\text { Description of action } \\
\text { (english) }\end{array}$ & $\begin{array}{l}\text { Ambi- } \\
\text { dexterity }\end{array}$ & $\begin{array}{l}\text { Paradoxical } \\
\text { leadership }\end{array}$ \\
\hline 8 & 13.03 .12 & $16: 50$ & $17: 00$ & $\begin{array}{l}\text { Reads task diary for } \\
\text { the day, compares with } \\
\text { last week and prepares } \\
\text { to do list }\end{array}$ & XPLOI & $\begin{array}{l}\text { Directive } \\
\text { (organises) }\end{array}$ \\
\hline 10 & 09.03 .12 & $9: 44$ & $9: 55$ & $\begin{array}{l}\text { Briefing with } \\
\text { employee and } \\
\text { discussion with respect } \\
\text { to important events } \\
\text { from last week }\end{array}$ & XPLOI & $\begin{array}{l}\text { Participatory } \\
\text { (exchanges } \\
\text { information } \\
\text { and opinion) }\end{array}$ \\
\hline 10 & 09.03 .12 & $9: 55$ & $10: 02$ & $\begin{array}{l}\text { Meeting with } \\
\text { marketing manager to } \\
\text { discuss increasing the } \\
\text { variety of products and } \\
\text { outsourcing } \\
\text { possibilities }\end{array}$ & $\mathrm{X}$ & $\begin{array}{l}\text { Participatory } \\
\text { (exchanges } \\
\text { information } \\
\text { and opinion) }\end{array}$ \\
\hline 10 & 09.03 .12 & $10: 02$ & $10: 10$ & $\begin{array}{l}\text { Reads and responds to } \\
\text { e-mails about the } \\
\text { opening of a } \\
\text { subsidiary in Berlin. } \\
\text { Addresses issues for } \\
\text { the opening and hiring } \\
\text { new staff }\end{array}$ & $X$ & $\begin{array}{l}\text { Participatory } \\
\text { (exchanges } \\
\text { information } \\
\text { and opinion) }\end{array}$ \\
\hline 11 & 16.03 .12 & $16: 13$ & $16: 15$ & $\begin{array}{l}\text { Conversation about } \\
\text { managing director of } \\
\text { restaurant; managing } \\
\text { director needs to be } \\
\text { trained further }\end{array}$ & $X$ & $\begin{array}{l}\text { Participatory } \\
\text { (exchanges } \\
\text { information } \\
\text { and opinion) }\end{array}$ \\
\hline 11 & 16.03 .12 & $16: 15$ & $16: 16$ & $\begin{array}{l}\text { Phone call of } \\
\text { subcontractor, briefly } \\
\text { organises the delivery }\end{array}$ & XPLOI & $\begin{array}{l}\text { Directive } \\
\text { (organises) }\end{array}$ \\
\hline
\end{tabular}

Note. $\mathrm{X}=$ Exploration; $\mathrm{XPLOI}=$ Exploitation 
This is a post-print version ${ }^{1}$. This article may not exactly replicate the final version published in the journal. The final peer-reviewed and edited copy of this manuscript is available here:

https://doi.org/10.1177/0266242620943371

\section{Table 3}

Means $(M)$, standard deviations $(S D)$, and correlations of variables

\begin{tabular}{lllllllll}
\hline Variables & $M$ & $S D$ & 2 & 3 & 4 & 5 & 6 & 7 \\
\hline & $\begin{array}{l}\text { Between- } \\
\text { person }\end{array}$ & & & & & & & \\
\\
variables
\end{tabular}

Note. Correlations below the diagonal are based on within-person (level one) data $(N=$ 384), and correlations above the diagonal are based on between-person (level two) data $(N=12),{ }^{*} \mathrm{p}<0.05 ; * \mathrm{p}<0.01$. 
This is a post-print version ${ }^{1}$. This article may not exactly replicate the final version published in the journal. The final peer-reviewed and edited copy of this manuscript is available here:

https://doi.org/10.1177/0266242620943371

\section{Table 4}

Results of multilevel modelling analysis predicting ambidexterity

$\begin{array}{ll}\text { Random intercept and } & \text { Random intercept and } \\ \text { fixed slope model } & \text { random slope model }\end{array}$

Predictors

Coefficients SE

Coefficients SE

Intercept

$\beta_{00} \quad 13.17^{* *}$

$13.15^{* *}$

Within-person (level 1) control

variable

$\begin{array}{llllll}\text { Directive leadership } & \beta_{10} & 1.16^{*} & 0.58 & 1.1 \uparrow & 0.58 \\ \text { Participative leadership } & \beta_{20} & 2.21^{* *} & 0.26 & 2.18^{* *} & 0.26 \\ \text { Paradoxical leadership } & \beta_{30} & 0.13 \dagger & 0.08 & 0.29 * & 0.11 \\ \text { (Directive x Participative) } & & & & & \end{array}$

Between-person (level 2)

variable

Life cycle stage

$\beta_{01}-4.63$

4.61

$-4.61$

4.61

Cross-level predictor (level $2 \mathrm{x}$

level 1)

Life cycle stage $\mathrm{x}$

$\beta_{31}$

$-0.28 *$

0.1

Paradoxical Leadership

Note. $N=384$ within-person measurements nested within 12 entrepreneurs. Coefficients with standard errors (SE) are shown, $* \mathrm{p}<.05 ; * \mathrm{p}<.01$. 
This is a post-print version ${ }^{1}$. This article may not exactly replicate the final version published in the journal. The final peer-reviewed and edited copy of this manuscript is available here:

\section{Appendix}

\section{Detailed information about lexical content analyses and linguistic word count} software.

Overall, the three temporal categories (past, present, and future) in the German dictionary contain 2820 words (e.g., "does" for the category present, "did" for the category past, and "will do" for the category future) that are used as comparisons to assess the occurrence of temporal words within a transcribed action unit. The LIWCcategories past and present have considerably larger lexica (i.e., $N=1,168$ for the past category; $N=1,683$ for the present category) in comparison to the future category ( $N=$ 14), which makes them more suitable to detect word occurrences in a given text. Previous studies have shown that these categories have been linked to the relevant psychological correlates, that is, the past category has been linked to show a focus on the past, present has been linked to living in the here and now, and future to future and goal-oriented correlates (Tausczik and Pennebaker, 2010).

The LIWC-categories tentative (e.g., "maybe," "perhaps," "guess") and money (e.g., "account," "sales," "shareholder," "cash") build on a 92 word and 192-word lexica, respectively. The overall transcript of activities (cf., table one) covered 46,069 words, with 34,991 words written to describe exploitation activities, and 11,078 words written to describe exploration activities. We calculated the percentage of words mapping on one of the five LIWC categories for each activity (on average 10.67 words were used to describe one activity). In a second step, we calculated the overall average level of percentages within each LIWC-category separately, with activities coded as either exploration versus exploitation. Independent t-tests were used to test statistically significant differences. 